\title{
The menstrual cycle and components of human female sexual behaviour
}

\author{
Elizabeth M. Hill \\ Program in Evolution and Human Behavior, University of Michigan, USA
}

In non-human primates, gonadal hormones alter attractivity and proceptivity to produce maximal sexual interaction around ovulation. A review of the relevant literature for humans revealed little comparable data. Hormonal correlations with human sexual behaviour have been difficult to demonstrate, and the most prominent peak of conscious sexual desire appears to occur in the mid-follicular rather than the ovulatory phase. There is evidence, however, for a mid-cycle peak in female sexual initiation. We suggest that the notion of non-cyclicity in humans may result from a lack of research concentration on separate components of sexual receptivity and on socio-environmental factors that may interact with hormonal influences.

\section{Introduction}

Psychobiology researchers have long been interested in the effects of hormonal changes during the menstrual cycle on human female sexual behaviour. In other mammals, females are most sexually receptive around ovulation, when fertilization is likely. It is generally believed that humans have no circumscribed phase of sexual receptivity. Many studies have failed to find dramatic evidence of hormonal influence, including both hormone replacement studies and studies of the menstrual cycle. The lack of cyclicity has been used as a hallmark contrast between humans and other primates (Campbell, 1985; Pfeiffer, 1985). Yet the menstrual cycle is assumed to affect many other behaviours of women (Friedman, 1982), and there is recent evidence of premenstrual behaviour in some primates similar to that of some women (Hausfater \& Skolblick, 1985).

Thus, extensive research remains inconclusive. There are several comparative analyses that could considerably clarify the precise differences between humans and non-human primates in cyclic sexual behaviour patterns. First, the dependent variables applied in human research are much less specific than the measures used in studies with other primates. Second, primate researchers have separated the components of sexual behaviour in order to examine independent hormonal influences. Third, the degree to which hormones control these components is affected by the conditions under which sexual cyclicity is studied. This review of the literature examines human behaviour within a comparative framework, in an attempt to specify primate-human differences in cyclicity and some of the proximal mechanisms.

Correspondence and request for reprints should be addressed to: Elizabeth Hill, Program in Evolution and Human Behavior, 1522 Rackham Building, University of Michigan, Ann Arbor, MI 48109, USA. 


\section{Coital patterns during the menstrual cycle}

Many non-human primates will copulate outside circumscribed oestrus periods (Rowell, 1972; Lancaster, 1979; Miller, 1928), particularly in laboratory settings, as will be discussed below. More specific dependent measures (like ejaculations/test or mounts/ test) do show a pattern of mid-cycle increase, luteal decrease and often a secondary premenstrual peak (Michael, 1968; Loy, 1970; Michael \& Zumpe, 1970; Everitt \& Herbert, 1972). The frequency of copulations per day is highest at mid-cycle in captive great apes (lowland gorillas-Nadler, 1975; chimpanzees-Lemmon \& Allen, 1978; orang-utans-Nadler, 1978).

It is well known that human females can be receptive at any stage of the cycle, but research has revealed some rhythmic changes (Table 1). A lack of adequate statistical analyses in most studies creates interpretive problems, however. To summarize the 12 samples in Table 1, most (10 of 12) indicated some post-menstrual increase in the probability of coitus; in particular, intercourse rates may be highest around days 6-10 (Spitz et al., 1975; Markowitz \& Brender, 1977; Bancroft et al., 1983). About half of the studies show a luteal drop (eight of 12) or a mid-cycle peak (six of 12). Only four suggest a premenstrual increase.

One report indicates the promise in using more specific dependent variables: Spitz et al. (1975) included the 'number of intercourse experiences per intercourse day'. There was a mid-cycle peak in this variable that could be important, since intercourse on a given day was more likely in the post-menstrual phase than at mid-cycle in this small sample. More detailed dependent variables are clearly necessary before specific comparisons with non-human primates can be made.

\section{Hormonal influences on components of sexual receptivity}

For describing sexual behaviour in detail, an instructive paradigm can be borrowed from studies of other primates. Much progress has been made since Beach (1976) suggested separating female sexual response into three categories; attractivity, proceptivity and receptivity. Attractivity, generally measured by male responses, includes stimuli attracting males to the female, such as odours or coloration changes. Proceptivity includes female behaviours, such as approaching males or displaying species-specific solicitations, which initiate or maximize the occurrence of male sexual responses to the female. Receptivity is restricted to female responses facilitating the act of copulation, meaning maintaining appropriate postures long enough for intravaginal ejaculation.

In non-human primates, oestrogens, progesterone and androgens act in concert to produce maximal sexual interaction around ovulation. Oestrogens increase attractivity (Michael, 1968; Phoenix, 1973; Baum et al., 1977b) and progesterone counteracts this effect (Michael, 1968; Baum et al., 1977b; Steklis et al., 1983), possibly by acting locally in the vagina (Baum et al., 1976). Proceptivity is affected in a complementary manner; oestrogen and androgens increase (Herbert, 1968; Michael \& Zumpe, 1970; Michael \& Keverne, 1972; Everitt \& Herbert, 1975; Baum et al., 1977a) and progesterone decreases proceptive behaviour (Michael \& Keverne, 1972), resulting in high ovulatory levels of female invitation (Cochran, 1979; Harvey, 1983). Since the females are also attractive at this time, these approaches are effective in stimulating male interest. It appears that in field settings, female proceptivity consists primarily of female-initiated proximity and following of males (Cochran, 1979), possibly acting to bring odours within the range of male perception. In non-human primates, hormone levels appear to have little effect on receptivity (Baum et al., 1976, 1977a; Johnson \& Phoenix, 1976, 1978). 


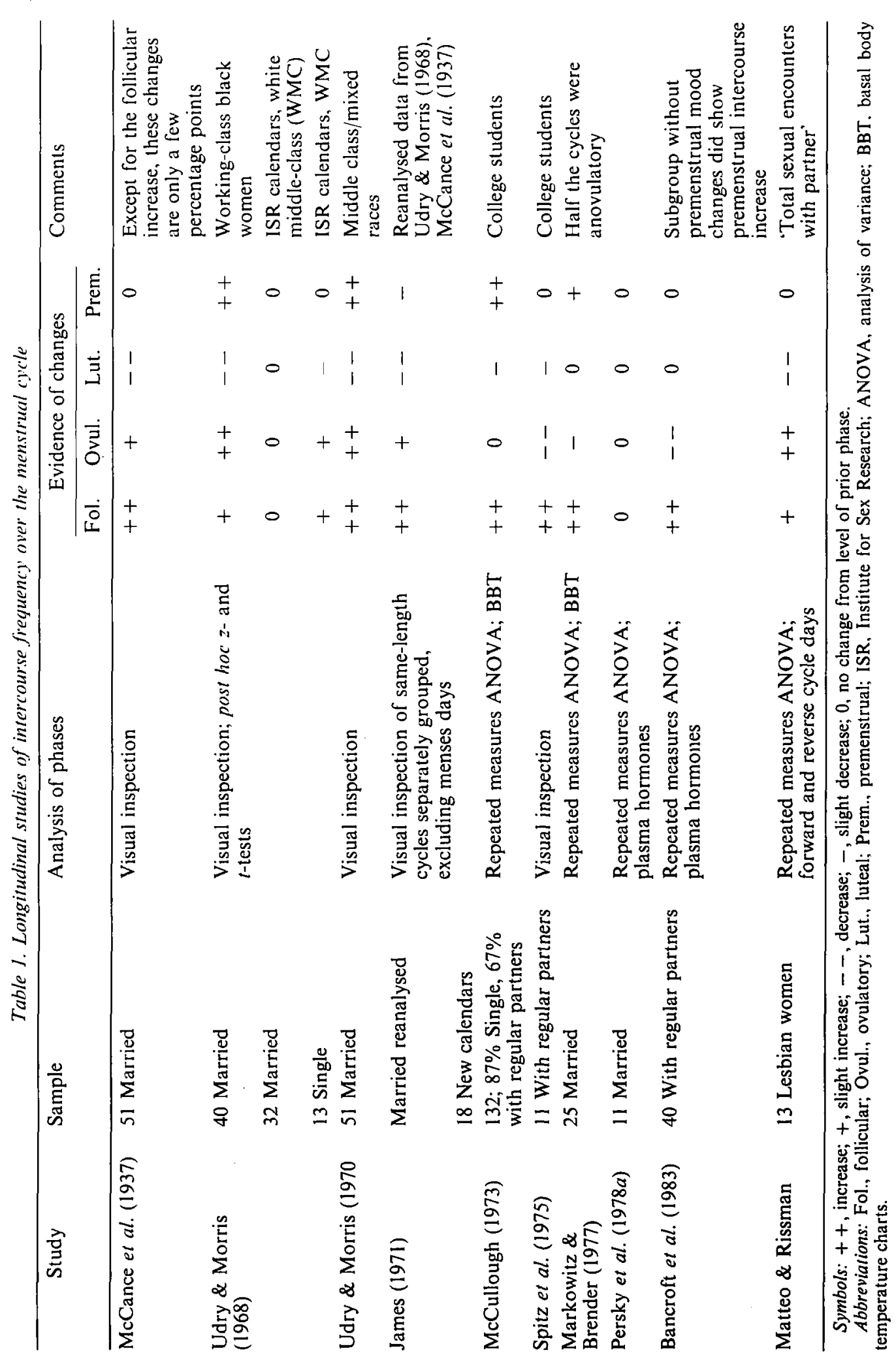




\section{Attractivity}

Few studies with humans have examined cyclic variations in male responses to females, and results have been inconsistent. Udry et al. (1973) reported daily data on whether husbands wanted intercourse, finding a mid-follicular and a mid-cycle peak, a luteal drop, then a premenstrual return to peak levels. A similar pattern, but with a mid-cycle drop, was found by Spitz et al. (1975) using male initiations combined with mutual initiations. In another report (Adams et al., 1978), male-initiated sexual activity increased near mid-cycle in a small group of married couples using an intra-uterine device or male vasectomy for contraception, but not in couples using other forms of contraception. In yet another study, however, male-initiated sexual behaviour showed a non-significant trend to be marginally greater in the luteal than in the follicular phase (Bancroft et al., 1983). Persky et al. (1978a) and Matteo \& Rissman (1984) found no differences in partner initiations that could be associated with changes in attractiveness over the cycle.

There is at present little evidence for an influence of hormones on human attractivity. Udry \& Morris (1970) reported that the decrease in sexual intercourse previously observed during the luteal phase of the cycle did not occur with women on contraceptive pills. They concluded (Udry et al., 1973) that the absence of a luteal suppression of coitus was probably due to the absence of the high levels of endogenous progesterone which normally would reduce the female's attractiveness, since endogenous progesterone would be inhibited by the exogenous hormones during a pill cycle. Persky et al. (1978a), however, found no relationship of oestrogen or progesterone to attractiveness; wives' levels of these hormones had no correlation with husbands' sexual initiation scores from biweekly clinical interviews. Thus, assessing the influence of hormones on human female attractivity must await better behavioural definitions and more consistent methodology.

\section{Proceptivity}

Human proceptive behaviour has been examined only recently. Due to taboos surrounding sexual topics, past researchers relied on retrospective questionnaires. In early studies, only a third of married women admitted having sexual desires; those who could mentioned periods of desire before and after menstruation (Davis, 1926, 1929). More modern samples do not contradict these findings (Terman, 1938; Ford \& Beach, 1951; Hart, 1960; Ferraro \& LaPietra, 1971; McCullough, 1973; but see Gupta \& Lynn, 1972).

The unreliability of retrospective memory is well documented (McCance et al., 1937; Englander-Golden et al., 1980). Longitudinal studies of changes in sexual desire are listed in Table 2 . These studies generally show a post-menstrual rise, then a slight and variable luteal decrease. Daily ratings of items related to sexual arousal did show a significant mid-cycle peak for women who were unaware of the menstrual cycle focus of the study (Englander-Golden et al., 1980). One sophisticated study (Sanders et al., 1983) separated premenstrual mood changes from sexuality by factor analysis. Daily sexual interest independent of mood change was maximal during days 6-10 and 23-28.

Because of difficulties in the reliable self-report of sexual interest, psychoanalyists have examined dreams, free-associative material and fantasies to determine the unconscious existence of sexual desire. Benedek \& Rubenstein (1939; Benedek, 1952) concluded that increasing oestrogen at the beginning of the cycle is associated with conscious sexual desire, and that luteal progesterone diminishes active sexual desire. The premenstrual decrease of progesterone then unmasks the effects of oestrogen, resulting in a recurrence of sexual awareness. This recurrence was not seen when both hormones declined simultaneously, according to their results. A relationship between subconscious material and 
the menstrual cycle was essentially corroborated by Cavanagh (1969) in psychoanalytic studies of 30 patients.

Recent studies have attempted to examine female proceptivity in a manner comparable to studies with other primates, recording behaviour rather than desire. Adams et al. (1978) reported that total autosexual activity and female-initiated heterosexual behaviour peaked near mid-cycle, 13-15 days before the next menstruation. The female initiation category also included mutally initiated activities, caressing sessions and female advances rejected by partners. Other authors have extensively criticized their methods (Kolodny \& Bauman, 1979; Persky et al., 1979; Tessman, 1979). Recently, Bancroft et al. (1983) reported that initiation by the woman or mutual initiation by both partners was most likely to occur in the mid-follicular phase (days 6-10). Matteo \& Rissman (1984) reported a significant mid-cycle peak and luteal drop in female-initiated sexual encounters. There were no post- or premenstrual increases and no menstrual decrease for this sample of women.

Other studies failed to find any cycle-related paterns. Spitz et al. (1975) reported that the frequency of sexual initiations by females in their study was too small to detect any meaningful changes through the cycle. Persky et al. (1978a) reported no variations in 'sexual gratification' daily ratings, nor did Abplanalp et al. (1979a) on 'enjoyment of sexual activities with partner'.

There is some evidence that hormones influence human proceptivity. Sexual relationships seem to improve for as many women as they deteriorate after hysterectomy and bilateral ovariectomy (Dennerstein et al., 1977; Martin et al., 1980; Gath et al., 1982). Double-blind, placebo-controlled studies of oestrogen replacement do show some increases in self-reports of sexual desire and enjoyment (reviewed in Dennerstein \& Burrows, 1982). In regard to progesterone, Grant \& Pryse-Davies (1968) found a correlation between the level of progesterone in oral contraceptives and the side-effects of both depression and reduced sexual interest, which may be a result of mood disturbance (Cullberg, 1972). Attempts have failed, however, to relate endogenous changes in oestrogen or progesterone levels to sexual initiation scores from clinical interviews (Persky et al., 1978a) and enjoyment or number of heterosexual activities (Abplanalp et al., 1979b).

Early clinical findings implicated adrenal androgens in the control of female sexual behaviour (Greenblatt et al., 1942; Waxenberg et al., 1959). Contemporary studies are not conclusive (Sanders \& Bancroft, 1982). A significant positive correlation was found between mean plasma testosterone and ratings of sexual interest, but only in those women free of sexual problems (Bancroft et al., 1980). Persky et al. (1978b) dichotomized women on baseline and ovulatory levels of plasma testosterone, finding significant positive associations with coital frequency and self-rated 'sexual gratification'. In addition, Bancroft et al. (1983) found that mean testosterone levels, while showing no relationship to sexual activity with the partner, were associated with masturbation frequency.

\section{Receptivity}

Female responsivity, or sexual arousability, is the response closest to 'receptivity' that has been measured. The relationships between laboratory measures of physiological or subjective sexual arousal and actual behaviour are unknown, however (Hatch, 1979). Studies of self-reported sexual arousal have shown no cyclic changes. Several studies have obtained self-ratings of arousal resulting from viewing slides of men, sexually explicit slides or erotic slides. No differences were found contrasting groups of women, each tested in one phase of the menstrual cycle (Griffith \& Walker, 1975; Abramson 


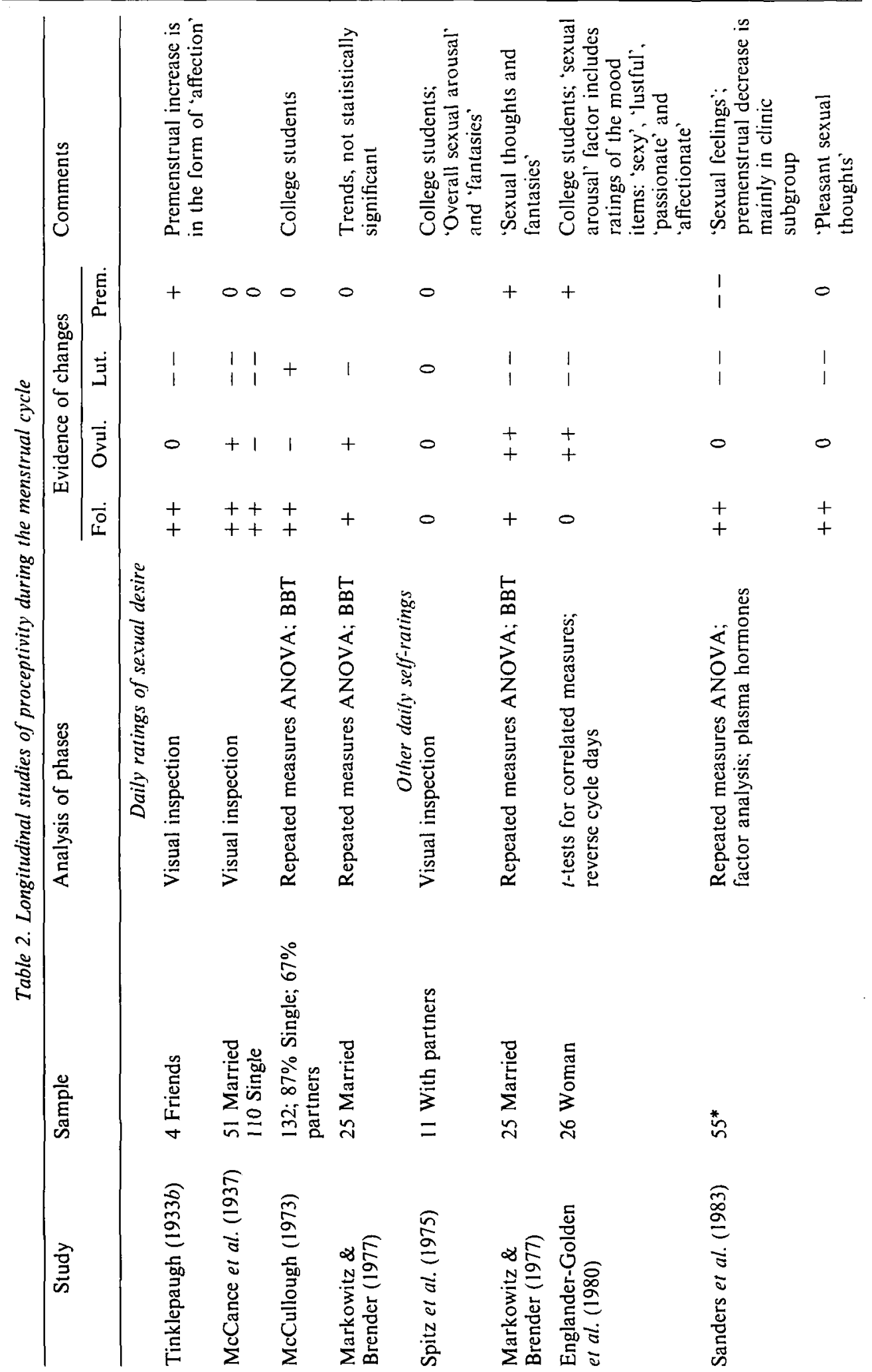




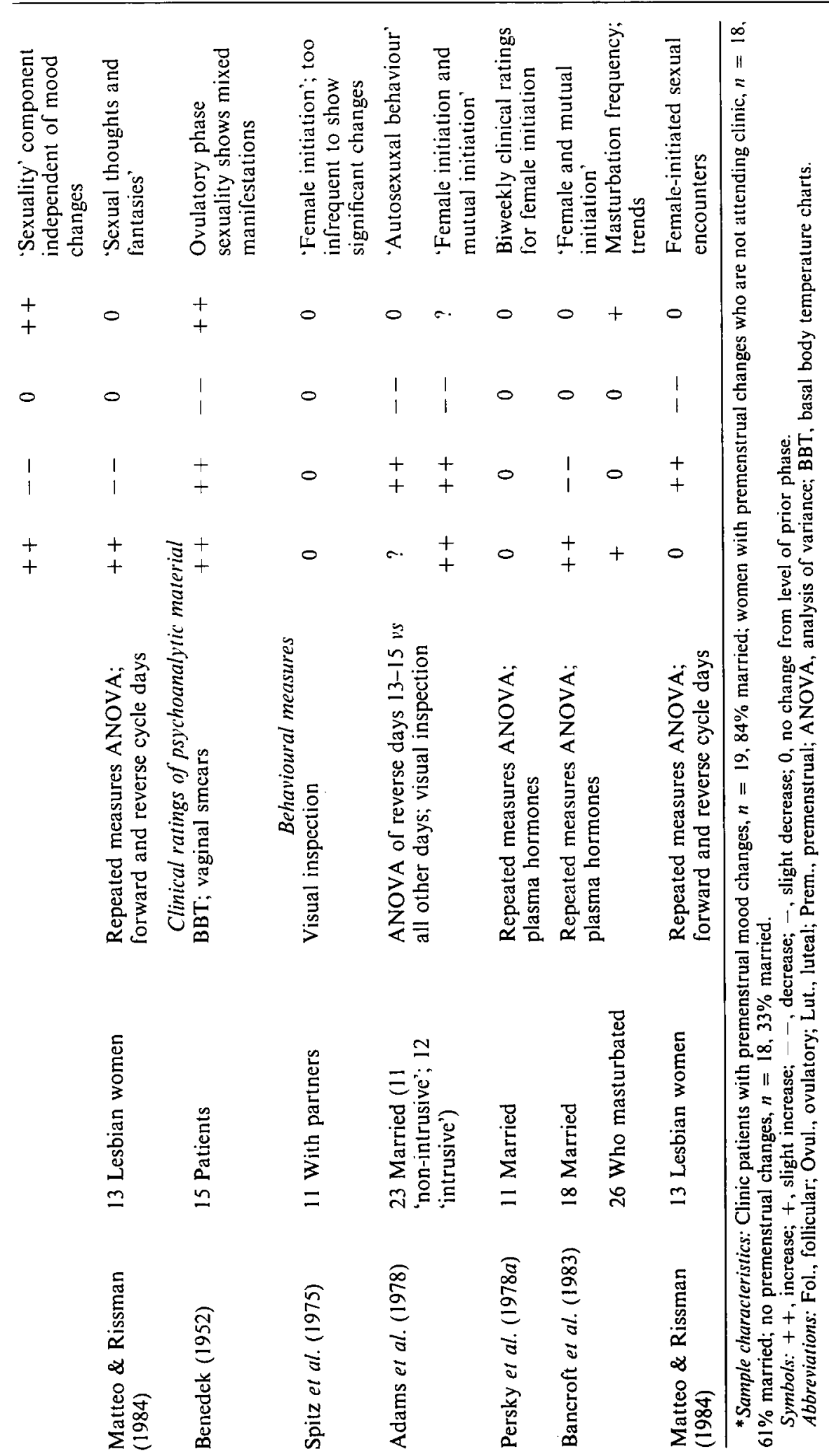


et al., 1976). Luschen \& Pierce (1972) reported higher ovulatory self-ratings, but this study is useless for the present purpose because they did not exclude women on birthcontrol pills.

Using physiological measures of arousal (vaginal photoplethmysmograph and labial temperature) in addition to self-reports, Hoon et al. (1982) found no differences in a longitudinal study of response to erotic audio tapes and fantasy. Two studies included plasma hormone samples (Schreiner-Engle et al., 1981; Morrell et al., 1984). SchreinerEngel et al. (1981) found no variation in self-reported arousal among the three periods tested (follicular, ovulatory and late luteal), but physiological arousability was lower around ovulation than during the follicular or late luteal phases. Morrell et al. (1984) found no cycle-related variation in physiological or subjective measures of arousal in response to erotic films and fantasy. They attributed their differences with SchreinerEngel et al. (1981) as a result of differences in sampling pulse amplitude values.

There is little evidence that hormones influence human receptivity. Schreiner-Engel et al. (1981) reported correlations between estradiol and progesterone and arousal that were mainly low and negative, Although the overall correlations between plasma testosterone and sexual arousal were low and non-significant, vaginal responsiveness was higher in women with higher testosterone levels, particularly in the mid-luteal phase.

This lack of striking cyclic change or hormonal influence is fairly consistent with non-human primate research. Dependent measures of receptivity would be the least likely component to show cycle-related variations. The finding of lower physiological arousability around ovulation needs further exploration, however, as does the role of baseline testosterone level. One problem in interpreting vaginal photoplethmysmograph pulse amplitude values is that baseline measures of these values show a mid-cycle peak that is also present in digital recordings (Palti \& Bercovici, 1967). This peak has been interpreted as a result of peripheral vascular dilation caused by oestrogen (Palti \& Bercovici, 1967). The high mid-cycle baseline values could make detecting an increase in a stimulated condition difficult.

\section{The interaction of testing conditions with hormone effects}

Socio-environmental factors may modify the degree to which hormonal effects on behaviour are discernable. Nadler (1981) reviewed data supporting the early hypothesis of Yerkes (1939) that primate mating extends outside the periovulatory period when males, rather than females, are the sexual initiators. Johnson \& Phoenix (1978) also suggested that the more completion of copulation depends on the female, the more likely are cyclic variations.

The idea of male-female control differentials has been used to compare relative degrees of cyclicity seen among great ape species. Whereas female chimpanzees and gorillas play an important part in the control of mating in their natural environment, orang-utan males frequently forcefully copulate with females. Cyclic variations in mating are usually much less apparent in orang-utans (Nadler, 1977), but, when testing conditions were arranged to allow females to initiate mating by crawling through a passage too small for the male, copulation took place primarily during the mid-cycle period (Nadler et al., 1980).

Steklis et al. (1983) reviewed supportive evidence for macaque species. In stumptail macaques, treatment of the female with medroxyprogesteronc (MPA) failed to produce significant differences in sexual behaviour in male-female pair test, while copulation decreased substantially for MPA-treated females in a social group (Steklis et al., 1983). 
Similarly, proceptivity and attractivity of stumptail macaques showed no significant variation over the menstrual cycle in laboratory tests (Slob et al., 1978a, b) but showed significant mid-cycle increases in a large, stable heterosexual group (Harvey, 1983). With pigtail macaques, female proceptive behaviours showed no relationship to the phase of the menstrual cycle or hormone levels in pair tests (Easton \& Resko, 1974), but they did vary with cycle phase when the females were tested with more than one male (Goldfoot, 1971). In social groups of rhesus, copulations were limited to the follicular and periovulatory phases (Gordon, 1981), and females exhibited an abrupt cessation of sexual invitations during the luteal phase (Cochran, 1979).

Wallen (1982) proposed that the limited area available in a test cage could interfere with spatial cues used by rhesus monkeys to communicate sexual interest, in addition to preventing the female from avoiding the male. He therefore tested male-female pairs in standard small laboratory cages or in larger chambers, comparing sexual behaviour during the females' follicular and luteal phases. Sexual behaviour dramatically decreased during the luteal phase when pairs were tested in the larger arena but not when tested in the small cage.

The cohabitation situation of marriage may shift the determinants of intercourse to receptivity, rather than proceptivity or attractivity. A man and woman are already in physical proximity, a state that is dependent on attractivity and proceptive behaviours for other primates in field settings. As discussed above, cycle-related changes in receptivity are very subtle. Most human research has employed married women. In other studies, results are not separately presented for single and married women. Spitz et al. (1975) did not indicate whether or not their 11 undergraduate subjects were married, but each had an ongoing heterosexual relationship. Most of McCullough's (1973) undergraduate sample was single, over half with regular sexual partners; the highest absolute frequency of intercourse was in the late luteal phase. Bancroft et al. (1983) did not report single/married groups, and marital status was slightly confounded with premenstrual mood change groups.

The influence of 'testing conditions' needs to be examined in human research on sexual behaviour cycles (Steklis, 1980). There is some indication that women in a Kalahari hunter-gatherer society exhibited a significant mid-cycle peak in sexual activity (Worthman, 1978; cited in Hrdy, 1981 and Konner, 1982). As with other primates, intercourse cycles may be more pronounced in samples of females with relatively more control over sexual encounters. Morris \& Udry (1978) reported their impression that less cyclicity is shown by more educated samples, but they have not yet published a systematic analysis of this hypothesis. The human samples with marked cyclicity in intercourse frequency were black women (Udry \& Morris, 1968, 1970), rather than the typical samples of white middle-class women. Roebuck \& McGee (1977) differentiated the marital power characteristics of one sample of black families into $37 \%$ matriarchal, $20 \%$ patriarchal and the rest equalitarian. It may be that the black females studied by Udry \& Morris $(1968,1970)$ exerted greater control over sexual interactions. The study of lesbian couples by Matteo \& Rissman (1984) indicates that increased sexual activity does occur at mid-cycle when there is more female control, if we assume these relationships are more egalitarian than typical heterosexual marriages. Future research could further test this hypothesis by determining which partner usually controls the occurrence of intercourse.

\section{Conclusions}

Without experimental studies with humans that are comparable to those with other primates, it is difficult to summarize the effects of hormones on the components of sexual 
behaviour for our own species. Existing data contain many inconsistencies that can only be clarified by further research employing different methodology. Subjects have generally been aware they were participating in a menstrual cycle study, knowledge possibly biasing self-report data (Ruble, 1977; Englander-Golden et al., 1980). Most pervasively, data analysis has been infused with much variability by reliance on menstrual markers to infer hormone levels (Udry \& Morris, 1977). Apart from these methodological problems, most studies have focused on married couples and have used as dependent variables intercourse occurrence or self-reported sexual desire. Cyclic variations could be less pronounced in marital sexual behaviour, since these interactions may depend most on receptivity. Sexual desire has not been directly related to the probability of intercourse, and its importance as a variable may depend on the degree of control exerted by particular females. Few studies have investigated female attractiveness and proceptivity, and these components should be explored in future research.

In summary, existing evidence for hormonal control of human sexual behaviour along the menstrual cycle is not overwhelming among the married couples usually studied. The average levels of hormones have been shown to have some influence, however, particularly androgen. There is some evidence that oestrogen plays a permissive role, and that progesterone has some inhibitory effect that may be mediated through mood changes. Sexuality appears to increase when progestrone is absent (low premenstrually and in the follicular phase) and oestrogen or androgen is present. Peaks of androgen and oestrogen secretion have been reported at mid-cycle and in the late luteal phase (O'Connor et al., 1974; Persky et al., 1977; Genazzi et al., 1978).

When behavioural measures are used, subtle patterns do appear that were not seen when self-reports of feelings or the simple occurrence of intercourse were used as dependent variables. Peaks in sexual activity at mid-cycle and in the premenstrual phase correlate with hormonal changes and are similar to patterns shown by other primates. The post-menstrual peak in sexual fantasies or activity may have a cultural rather than hormonal basis. Gold \& Adams (1981) found a post-menstrual peak in coitus only among couples who abstrained from intercourse during menses. Both abstainers and non-abstainers showed a premenstrual peak, however. The women studied by Matteo \& Rissman (1984), who were non-abstainers, showed no post-menstrual peak.

Baum et al. (1977b) suggested that cyclic sexual behaviour in other primates can be fully accounted for by changes in attractivity. Some primates have visual or olfactory signals that correlate with ovulation (Michael \& Bonsall, 1979; Graham, 1981; but see Goldfoot et al., 1976). Studies of human attractivity are inconclusive. The importance of cyclic olfactory cues has not been convincingly demonstrated with humans (Morris \& Udry, 1978), and the artificial diminution of this factor could be an important inter-species difference as a concomitant of contemporary hygiene practices. Tinklepaugh $(1933 b)$ had discerned a peak in 'nonsexual affection' during the premenstrual period. Other researchers, analysing the content of subjects' undirected five-minute discourse, have found a premenstrual increase in yearning for love and anxiety about separation from love (Ivey \& Bardwick, 1968). In human pairs, such affection could easily lead to coitus, since female attractiveness appears not to vary over the cycle.

Proceptive behaviour, which appears to increase at mid-cycle, may differ from sexual feelings. Conscious female sexual desire appears to increase during the mid-follicular phase, and for some in the premenstrual period. Again, better measures than self-reports of desire are necessary. Benedek's $(1939,1952)$ psychoanalytic studies had predicted that desire would become less conscious at mid-cycle or be manifested as tenseness and anxiety. In Sanders et al. (1983), the appearance of a high level of sexual feelings at 
ovulation was due primarily to the subgroup of women who were attending a clinic for premenstrual syndrome, while the independent 'sexuality' component showed the midfollicular increase and ovulatory decrease for all groups. Perhaps women whose moods may be elated by high oestrogen levels reflect this influence in their self-ratings of conscious sexual feelings, a pattern which is not shown by women whose moods are unaffected by oestrogen.

In conclusion, ovulation appears to be somewhat concealed and receptivity to be rather impervious to hormonal variations, as it is with other primates; but we fit on a continuum from circumscribed oestrus to flexible receptivity, rather than anchoring either extreme (Hrdy, 1983). Again, women in naturalistic settings who must be proceptive to gain proximity to men and who have control of sexual interactions have not been sufficiently studied; for these, there could be real cyclic changes corresponding to hormonal variations. Effort should be expended to collect data on sexual cycles in non- Western societies (Gray \& Wolfe, 1983). Given the subtle patterns in sexual activity that this review has shown, more sexual activity outside ovulation could partially be a side-effect of continuous male-female proximity in a system of unvarying female attractiveness.

\section{Acknowledgements}

Portions of this review were presented at the Animal Behaviour Society Meetings, Nashville, Tennessee, 1981. Drs Terry Christenson, Janis Dunlap, Peter Volpe and Elizabeth Watts gave helpful comments on earlier drafts. Preparation of this article was supported by National Institute of Health Grants MH 14612-07 and HL07567-02.

\section{References}

Abplanalp, J. M., Donnelly, A. F. \& Rose, R. M. (1979a). Psychosom. Med. 41, 587-604.

Abplanalp, J. M., Rose, R. M., Donnelly, A. F. \& Livingston-Vaughn, L. (1979b). Psychosom. Med. 41, 605-615.

Abramson, P. R., Repezynski, C. A. \& Merrill, L. R. (1976). J. consult. clin. Psychol. 44, 10181019.

Adams, D. B., Gold, A. R. \& Burt, A. D. (1978). New Eng. J. Med. 299, 1145-1150.

Bancroft, J., Davidson, D. W., Warner, P. \& Tyrer, G. (1980). Clin. Endocrinol. 12, 327-340.

Bancroft, J., Sanders, D., Davidson, D. \& Warner, P. (1983). Psychosom. Med. 45, 509-516.

Baum, M. J., Everitt, B. J., Herbert, J., Keverne, E. B. \& de Greef, W. J. (1976). Nature 263, 606-608.

Baum, M. J., Everitt, B. J., Herbert, J. \& Keverne, E. B. (1977a). Arch. sex. Behav. 6, 173-192.

Baum, M. J., Keverne, E. B., Everitt, B. J., Herbert, J. \& de Greef, W. J. (1977b). Physiol. Behav. 18, 659-6709.

Beach, F. A. (1976). Arch. sex. Behav. 5, 469-485.

Benedek, T. (1952). Psychosexual Functions in Women. New York: Ronald.

Benedek, T. \& Rubenstein, B. B. (1939). Psychosom. Med. 1, 245-322.

Campbell, B. G. (1985). Humankind Emerging, 4th edn. Boston: Little, Brown \& Co.

Cavanaugh, J. R. (1969). Med. Aspects hum. Sex. 3, 29-39.

Cochran, C. G. (1979). Behav. neural Biol. 27, 342-353.

Cullberg, J. (1972). Acta psychiat. Scand. (Suppl. 236).

Daniels, D. (1983). Ethol. Sociobiol. 4, 69-87.

Davis, K. B. (1926). Am. J. Obstet. Gynecol. 12, 834-838.

Davis, K. B. (1929). Factors in the Sex Life of Twenty-Two Hundred Women. New York: Harper.

Dennerstein, L. \& Burrows, G. D. (1982). Clin. Endocrinol. Metab. 11, 661-679.

Dennerstein, L., Wood, C. \& Burrows, G. D. (1977). Obstet. Gynecol. 49, 92-96.

Eaton, G. C. \& Resko, J. A. (1974). J. comp. Physiol Psychol. 86, 919-925.

Englander-Golden, P., Chang, H.-S., Whitmore, M. R. \& Dienstbier, R. A. (1980). J. hum Stress $6,42-48$. 
Everitt, B. J. \& Herbert, J. (1972). Danish med. Bull. 19, 246-258.

Everitt, B. J. \& Herbert, J. (1975). Brain. Res. 86, 109-120.

Ferrero, G. \& LaPietra, O. (1971). Panminerva Med. 13, 407-409.

Ford, C. S. \& Beach, F. A. (1951). Patterns of Sexual Behaviour. New York: Harper.

Friedman, R. (Ed.) (1982). Behavior and the Menstrual Cycle. New York: Marcel Dekker.

Gath, D., Cooper, P. \& Day, A. (1982). Br. J. Psychiat. 140, 335-350.

Genazzi, A. R., Devoto, M. C., Gianchett, C., Pintor, C., Facchinette, F., Mangoni, A. \& Fiorett, P. (1978). In (L. Carenza, P. Pancheri \& L. Zichella, Eds): Clinical Psychoendocrinology in Reproduction. New York: Academic Press.

Gold, A. R. \& Adams, D. B. (1981). Psychol. Women Q. 5 (Suppl.), 670-680.

Goldfoot, D. A. (1971). In (G. B. A. Stoelinger \& J. J. Van der Werfften Bosch, Eds): Normal and Abnormal Developments of Brain Behaviour. Leiden: University of Leiden.

Goldfoot, D. A., Kravetz, M. A., Goy, R. W. \& Freeman, S. K. (1976). Horm. Behav. 7, 1-27.

Gordon, T. P. (1981). Am. Zool. 21, 185-195.

Graham, C. E. (1981). In (C. E. Graham, Ed.): Reproductive Biology of the Great Apes: Comparative and Biomedical Perspectives. New York: Academic Press.

Grant, E. C. G. \& Pryse-Davies, J. (1968). Br. med. J. iii, 777-780.

Gray, J. P. \& Wolfe, L. D. (1983). J. soc. biol. Struct. 6, 345-352.

Greenblatt, R. B., Mortara, F. \& Torpin, R. (1942). Am. J. Obstet. Gynecol. 44, 658-663.

Griffith, M. \& Walker, C. E. (1975). Arch. sex Behav. 4, 599-603.

Gupta, A. S. \& Lynn, D. B. (1972). J. sex. Res. 8, 207-218.

Hart, R. D. (1960). Br. med. J. 1, 1023-1024.

Harvey, N. C. (1983). In (H. D. Steklis \& A. S. Kling, Eds): Hormones, Drugs and Social Behaviour in Primates. New York: Spectrum.

Hatch, J. P. (1979). Arch. sex. Behav. 8, 357-374.

Hausfater, G. \& Skolblick, B. (1985). Am. J. Primatol. 9, 165.

Hoon, P. W., Bruce, K. \& Kinchloe, B. (1982). Psychophysiology 19, 21-26.

Hrdy, S. B. (1981). The Woman That Never Evolved. Cambridge, Massachusetts: Harvard University.

Hrdy, S. B. (9183). Science 83, 4 (8), 72-78.

Ivey, B. E. \& Bardwick, J. M. (1968). Psychosom. Med. 30, 336-345.

James, W. H. (1971). J. biosoc. Sci. 3, 159-171.

Johnson, D. F. \& Phoenix, C. H. (1976). J. comp. Physiol. Psychol. 90, 473-483.

Johnson, D. F. \& Phoenix, C. H. (1978). Horm. Behav. 11, 160-174.

Kolodny, R. C. \& Bauman, J. E. (1979). New Eng. J. Med. 300, 626.

Konner, M. (1982. The Tangled Wing: Biological Constraints on the Human Spirit. New York: Holt, Rinehart \& Winston.

Lancaster, J. B. (1979). In (H. A. Katchadourian, Ed.): Human Sexuality: A Comparative and Developmental Perspective. Berkeley: University of California.

Lemmon, W. B. \& Allen, M. L. (1978). Fol. Primatol. 30, 80-88.

Loy, J. (1970). Fol. Primatol. 13, 286-297.

Luschen, J. E. \& Pierce, D. M. (1972). J. sex. Res. 8, 41-47.

Markowitz, H. \& Brender, W. (1977). In (R. Gemme \& C. C. Wheeler, Eds): Progress in Sexology. New York: Plenum.

Martin, R. L., Roberts, W. V. \& Clayton, P. J. (1980). J. Am. Med. Assoc. 244, 350-353.

Matteo, S. \& Rissman, E. F. (1984). Horm. Behav. 18, 249-254.

McCance, R. A., Luff, M. C. \& Widdowson, E. E. (1937). J. Hygiene 27, 571-611.

McCullough, R. C. (1973). Rhythms of sexual desire and activity in the human female. Unpublished Doctoral Dissertation, University of Oregon, Eugene.

Michael, R. P. (1968). In (R. P. Michael, Ed.): Endocrinology and Human Behaviour. London: Oxford.

Michael, R. P. \& Bonsall, R. W. (1979). In (C. Beyer, Ed.): Endocrine Control of Sexual Behaviour. New York: Raven.

Michael, R. P. \& Keverne, E. G. (1972). J. Endocrinol. 55, xl-xli.

Michael, R. P. \& Zumpe, D. (1970). J. reprod. Fert. 21, 199-201.

Miller, G. S. (1928). J. Mammol. 9, 273-293.

Morrell, M. J., Dixen, J. M., Carter, C. S. \& Davidson, J. M. (1984). Am. J. Obstet. Gynecol. 148, 66-71. 
Morris, N. M. \& Udry, J. R. (1978). J. biosoc. Sci. 10, 147-157.

Nadler, R. D. (1975). Science 189, 813-814.

Nadler, R. D. (1977). In (G. H. Bourne, Ed.): Progress in Ape Research. New York: Academic.

Nadler, R. D. (1978). In (D. J. Chivers \& J. Herbert, Eds): Recent Advances in Primatology, vol. 1, Behaviour. London: Academic Press.

Nadler, R. D. (1981). In (C. E. Graham, Ed.): Reproductive Biology of the Great Apes: Comparative and Biomedical Aspects. New York: Academic Press.

Nadler, R. D., Miller, L. C., Collins, D. C. \& Blank, M. S. (1980). Anthropol. Contemp. 3, 297.

O'Connor, J., Shelley, E. \& Stern, L. (1974). In (F. Halberg, M. Ferrin, R. Richart \& R. VandeWiele, Eds): New York: Wiley.

Palti, Y. \& Bercovici, B. (1967). Am. J. Obstet. Gynecol. 97, 143-153.

Persky, H., Charney, N., Lief, H., O’Brien, C. P., Miller, W. R. \& Strauss, D. (1978a). Psychosom. Med. 40, 523-535.

Persky, H., Lief, H., O'Brien, C., Strauss, D. \& Miller, W. (1977). In (R. Gemme \& C. Wheeler, Eds): Progress in Sexology. New York: Plenum.

Persky, H., Leif, H. I., Strauss, D., Miller, W. R. \& O'Brien, C. P. (1978b). Arch. sex. Behav. 7, 157-173.

Persky, H., O’Brien, C. P., Lief, H. I., Strauss, D. \& Miller, W. R. (1979). New Eng. J. Med. 300, 626.

Pfeiffer, J. E. (1985). The Emergence of Man, 4th edn. New York: Harper \& Row.

Phoenix, C. H. (1973). Horm. Behav. 4, 365-370.

Roebuck, J. \& McGee, M. G. (1977). J. sex. Res. 13, 104-114.

Rowell, T. E. (1972). Adv. Study Behav. 4, 69-105.

Ruble, D. N. (1977). Science 197, 291-292.

Sanders, D. \& Bancroft, J. (1982). Clin. Endocrinol. Metab. 11, 639-659.

Sanders, D., Warner, P., Backstream, T. \& Bancroft, J. (1983). Psychosom. Med. 45, 487-501.

Schreiner-Engel, P., Schiavi, R. C., Smith, H. \& White, D. (1981). Psychosom. Med. 43, 199-214.

Slob, A. K., Baum, M. J. \& Schenck, P. E. (1978a). Physiol. Behav. 21, 915-921.

Slob, A. K., Wiegard, S. J., Goy, R. W. \& Robinson, J. A. (1978b). Horm. Behav. 10, 191-211.

Spitz, C. J., Gold, A. R. \& Adams, D. B. (1975). Arch. sex. Behav. 4, 249-263.

Steklis, H. D. (1980). Behav. Brain Sci. 3, 199-200.

Steklis, H. D., Linn, G. S., Howard, S. M., Kling, A. \& Tiger, L. (1983). In (H. D. Steklis, \& A. S. Kling, Eds): Hormones, Drugs and Social Behaviour in Primates. New York: Spectrum.

Terman, L. M. (1938). Psychological Factors in Marital Happiness. New York: McGraw-Hill.

Tessman, I. (1979). New Eng. J. Med. 300, 626.

Tinklepaugh, O. L. (1933a). J. Morphol. 54, 521-546.

Tinklepaugh, O. L. (1933b). Am. J. Obstet. Gynecol. 26, 336-345.

Trimble, M. R. \& Herbert, J. (1968). J. Endocrinol. 42, 171-185.

Udry, J. R. \& Morris, N. M. (1968). Nature 220, 593-596.

Udry, J. R. \& Morris, N. M. (1970). Nature 227, 502-503.

Udry, J. R. \& Morris, N. M. (1977). J. reprod. Fert. 51, 419-425.

Udry, J. R., Morris, N. M. \& Waller, L. (1973). Arch. sex Behav. 2, 205-214.

Wallen, K. (1982). Science 217, 375-377.

Wallen, K. \& Goy, R. W. (1977). Horm. Behav. 9, 228-248.

Waxenberg, S. E., Drellich, M. G. \& Sutherland, A. M. (1959). J. Clin. Endocr. Metab. 19, 193-202.

Yerkes, R. M. (1939). Hum. Biol. ii, 78-111.

\section{Note added in proof}

After this article went to press, Carol M. Worthman presented the results of her unpublished 1978 dissertation work (Evolution and Human Behavior Conference, April, 1988). Eight Kung San women, followed over two menstrual cycles, self-reported periovulatory increases in proceptivity. Coital rate increased in the post-menstrual and periovulatory phases. 